\title{
A zooprophylaxis strategy using L-lactic acid (Abate) to divert host-seeking malaria vectors from human host to treated non-host animals
}

\author{
Elison E. Kemibala ${ }^{1,3^{*}}$, Agenor Mafra-Neto ${ }^{2}$, Teun Dekker ${ }^{4}$, Jesse Saroli ${ }^{2}$, Rodrigo Silva ${ }^{2}$, Anitha Philbert ${ }^{3}$, \\ Kija Nghabi ${ }^{3}$ and Leonard E. G. Mboera ${ }^{5}$
}

\begin{abstract}
Background: Zooprophylaxis is a technique in which blood-seeking vectors are diverted to non-host animals in order to lower blood-feeding rates on human hosts. The success of this technique depends on the host preference of the vector being targeted. The objective of this study was to evaluate the effect of L-lactic acid (Abate) to divert malaria mosquito, Anopheles gambiae from feeding on human host.
\end{abstract}

Methods: A 14-month-old female goat was treated with Abate, a formulation incorporating L-lactic acid into a slowrelease matrix. This formulation was applied on the fur of the goat's back and neck. The treated animal was then presented to Anopheles gambiae sensu stricto (s.s.) as a prospective host in a semi-field environment ('mosquito sphere') together with either an untreated animal or a human. The number of mosquitoes caught to each host choice offered were compared.

Results: Goat treated with the L-lactic acid formulation successfully attracted An. gambiae at higher rates (70.2\%) than the untreated ones (29.8\%). Furthermore, An. gambiae s.s. were attracted to a treated goat at an equivalent degree (47.3\%) as to their preferred human host (52.7\%), even when the preferred host was present in the same environment.

Conclusions: The findings indicate that human host-seeking mosquitoes can be diverted into feeding on nonpreferred hosts despite the close proximity of their favoured host, hence reducing chances for the transmission of blood-borne parasites.

Keywords: Mosquitoes, Malaria, Attractant, L-Lactic acid, Goats, Human host

\section{Background}

Malaria is a mosquito-borne disease placing a huge burden on public health especially in tropical regions of the world. In 2017, malaria caused an estimated 219 million clinical episodes and 435,000 deaths, with the 93\% of these deaths occurring in sub-Saharan Africa [1]. The most efficient malaria vectors in sub-Saharan Africa

\footnotetext{
*Correspondence: elisonmwebembezi@gmail.com

${ }^{1}$ Ministry of Health, Community Development, Gender, Elderly and Children, Vector Control Training Centre, Muheza, Tanzania Full list of author information is available at the end of the article
}

belong to the Anopheles gambiae sensu lato (s.l.) and Anopheles funestus species complexes [2]. The World Health Organization (WHO) currently recommends the use of long-lasting insecticide-treated mosquito nets and indoor residual spraying of insecticides to protect humans from mosquito bites [3]. For the past decade, massive scale-up of these two interventions has resulted in considerable progress in malaria control across subSaharan Africa [4]. However, sustainability of these interventions for year-round or long-term community protection is now facing several challenges [5]. These 
include difficulties in achieving the required coverage rates during hot and dry seasons, deterring mosquito net usage and routine household damage to nets compromising their protective efficacy [6, 7]. Moreover, IRS applications are logistically demanding and economically unsustainable in many malaria-endemic regions [8]. The increasing frequency of resistance of mosquitoes to insecticides used in mosquito nets and indoor residual spraying further threatens sustainable effectiveness of both strategies [9-12].

To address these challenges and achieve effective, sustainable malaria control, there is an urgent need for exploration of novel solutions to supplement the existing interventions [13]. A highly promising approach that has been explored intensively in recent years is the use of the "Attract and Kill" approach [14]. This approach deploys a two-part formulation i.e. a lure which can emulate vertebrate host odours, floral-based sugar sources or other attractant chemicals; and a lethal or incapacitating component. The lure draws the target mosquitoes to the application site, inducing it to contact and/or feed upon the attract and kill formulation and expose themselves to the control agent within. This exposure either kills or debilitates the mosquito, rendering it less capable of flight, feeding or mating [15].

Mosquitoes use olfactory cues such as carbon dioxide to locate and orient themselves to their blood hosts. However, carbon dioxide is not species specific, meaning that mosquitoes would not be able to distinguish between human and other animal hosts based on this cue [16-19]. Several chemical compounds including L-lactic acid, ammonia, 1-octen-3-ol and phenols have been reported as mosquito attractants [20-24]. Though L-lactic acid has been identified as one of the components contained in the skin and breath secretion of mammals, its concentration varies between different groups of mammals. While highly anthropophilic mosquitoes are attracted by higher concentrations of lactic acid, zoophilic ones are repelled by it [17].

Zooprophylaxis has been a key component in environmental management of mosquito-borne diseases $[25,26]$. In this technique, mosquitoes are diverted from humans to other mammals thus reducing individuals' susceptibility to such [26-28]. Therefore, availability of alternative sources of blood meal for parasite-carrying insects together with other protective measures will likely reduce disease transmission rates. This study, explored an approach to target adult mosquitoes using a zooprophylaxis strategy, deploying a lactic acid-based attractant formulation (Abate) a non-commercial product of the US-based ISCA Technologies Inc. designed to emulate the scent profile of human hosts to divert bloodseeking mosquitoes from people to goats. The study was designated to assess the effect of Abate to divert An. gambiae sensu stricto (s.s.) into feeding on an animal host, even in the presence of its favored human host.

\section{Methods \\ Study area}

This study was carried out in Muheza District located in the northeast of Tanzania. This district $\left(5^{\circ} 13^{\prime} \mathrm{S}, 38^{\circ} 39^{\prime} \mathrm{E}\right.$; altitude $193 \mathrm{~m}$ ) is characterized by a humid and warm climate almost throughout the year. The average annual rainfall in Muheza is $1000 \mathrm{~mm}$ with two seasonal peaks i.e. a main peak between March and May, and a less pronounced one between November and December. The mean temperature in the area is $26^{\circ} \mathrm{C}$. The cooler months are between June and September while the warmer ones are between October and May. The experiments were carried out in an insectary and in mosquito spheres (semi-field environment) at Amani Research Centre of the National Institute for Medical Research.

\section{Rearing mosquitoes for experiments}

Anopheles gambiae Kisumu strain, brought from Kenya Medical Research Institute (KEMR) were colonized and maintained in a controlled environment $\left[27 \pm 1{ }^{\circ} \mathrm{C}, 65 \pm 5 \%\right.$ relative humidity (RH), and at a 12 h:12 h light: dark cycle] at the Amani Research Centre since early 1982. Anopheles larvae were reared in plastic trays $(20 \mathrm{~cm} \times 30 \mathrm{~cm} \times 10 \mathrm{~cm})$ filled with distilled water in groups of 250 per tray and fed on fish food $\left(\right.$ Tetramin $\left.{ }^{R}\right)$ once a day. Adults were kept in cages $(30 \mathrm{~cm} \times 30 \mathrm{~cm} \times 30 \mathrm{~cm})$ with access to a $10 \%$ sucrose solution. To enable reproduction, female mosquitoes were blood-fed on rabbits according to Standard Operating Procedures approved by the Tanzania Medical Research Coordinating Committee. European Community guidelines and standards were followed in rabbit rearing [29].

\section{Experiment procedures}

Four stages of semi-field trials were conducted in the mosquito spheres [22]. Each sphere contained a mudmade and thatched hut large enough to comfortably house two prospective hosts. In this way, mosquitoes' response to choose a host pair treated with the lactic acid formulation (Abate) or not was assessed. In the first trial, a pair of untreated goats was placed in the sphere in order to establish a baseline Anopheles activity in the presence of natural-state, non-preferred animal host. In the second trial, Abate-treated and untreated goats were presented to assess the effect of lactic acid treatment on feeding behaviour of mosquitoes. This was followed by the placement of untreated goat and untreated human in the third trial sphere to demonstrate mosquito 
blood feeding behaviour when both preferred and nonpreferred hosts were present. This trial sphere was used to compare with host choice presented in the fourth and final semi-field study, during which an Abate-treated goat and untreated human were stationed inside the mosquito sphere. Goats used in these trials were both females, weighing about $14 \mathrm{~kg}$ each and both had white fur.

Each hut in the mosquito sphere had a wooden frame designed to accommodate two animal hosts. Two rectangular $(90 \mathrm{~cm} \times 50 \mathrm{~cm} \times 60 \mathrm{~cm})$ mosquito nets were used to cover each of the wooden frames during the experiment. Hosts were placed underneath the frames in opposite sides and untreated mosquito nets were draped over each host at the start of each experiment. Human host was not confined in the wooden frame rather covered with nets in a seated position inside the hut. The inner net was extended to the ground while the outer one was kept at about $8 \mathrm{~cm}$ from the hut's floor. The mosquito net was arranged with inner and outer layers which allowed testing of comparative level of mosquitoes' attraction to the presented hosts and limited their contact with the hosts. Meanwhile, hosts were confined within their assigned frames each night and were not shifted between nights. Mosquitoes captured between the two mosquito nets on each frame were collected using a vacuum aspirator hourly for $6 \mathrm{~h}$ from 18:00 h by technician worn a coverall to avoid interfering with mosquito's choice. At the end of each replicate hourly collected mosquitoes were combined for each choice offered and the totals were used for comparisons.

\section{Attractiveness of An. gambiae s.s. to untreated, non-preferred hosts}

In this experiment, two untreated female goats of similar colour and size (about $60 \mathrm{~cm}$ standing height), were placed in the hut beneath the designed frames. Specifically, each goat was placed in its own frame and a covering mosquito net. At 18:00 hours, a total of $500 \mathrm{An}$. gambiae sensu stricto (s.s.) mosquitoes, previously sugar starved for a period of 6 hours, were released into the sphere until 0:00 hours (midnight) when they were captured from each mosquito net for four consecutive nights. The number of mosquitoes captured between the two mosquito nets was compared to identify the differences in attractiveness between the two hosts. This experiment was repeated for four consecutive nights, with each night representing one replicate.

\section{Attractiveness of Anopheles gambiae s.s. to an Abate-treated goat}

This experimental setting was identical to the preceding one except that a prototype formulation of Abate was applied on the skin of one of the goats. About $100 \mathrm{~g}$ of the formulation mixed with $100 \mathrm{ml}$ of clean tap water was applied on the fur on the goat's back and neck using a paintbrush. An Abate-treated goat was then placed underneath one of the hut's mosquito net frames while the untreated goat (of the same size, age and relative health) was placed underneath the second net frame. A total of 200-400 female mosquitoes were released each night for at 18:00 hours in the evening and collected hourly until 0:00 hours. The collection of released mosquitoes continued for five nights consecutively with each night the treated goat was reapplied with Abate.

\section{Attractiveness of An. gambiae s.s. to human bait and Abate-treated goat}

In similar manner to the two preceding trials, an untreated human and goat were presented to starved An. gambiae s.s. for host selection. The goat was caged inside one of the netting frames while a human sat in the other. A total of 200-400 female starved An. gambiae s.s. mosquitoes were released into the mosquito sphere each night for five nights. After five replicates, the difference in attractiveness between human bait and untreated goat was assessed.

In another series of experiments, mosquitoes were left to choose between an Abate-treated goat and a human bait. The goat was confined in the frame and then covered with double mosquito. In the same hut, a human sat covered by a double-layered mosquito net. A total of 400-600 starved female An. gambiae s.s. were released into the mosquito sphere during each night for four night. Capturing of mosquitoes began an hour later and continued at hourly intervals until 0:00 hours for four consecutive nights. Application of Abate on goat's fur was repeated during each night.

\section{Data analysis}

Data were summarized in Microsoft Excel and then transferred to Stata software (StataCorp. 2013) for statistical analysis.

\section{Results}

Throughout the trial, a total of 5700 starved female $A n$. gambiae s.s. were released into the mosquito sphere. Of these, 4926 (86.4\%) mosquitoes were captured. In the first experiment, a total of 236 and 201 An. gambiae s.s. were collected from the nets covering untreated goat 1 and 2, respectively. There was no significant difference between the number of mosquitoes attracted to the two untreated goats (Table 1).

When comparing the Abate-treated goat to the untreated one (control); $70.24 \%$ of mosquitoes were captured from the net covering the treated goat and 
the remainder were recovered from the untreated goat (Table 2).

When comparing the mosquito responses to the presence of a human and untreated goat; a larger proportion (76.62\%) of the captured mosquitoes were caught while attempting to feed on the human host than on the goat (Table 3).

In the trial which compared mosquitoes' response to human versus to Abate-treated goat; $55 \%$ of the captured mosquitoes were caught in the human-baited net while the rest of mosquitoes were from the Abate-treated goat (Fig. 1).

Generally, the treated goat and human attracted a larger number of mosquitoes during the four trials. In the absence of preferable host, mosquitoes were forced to feed even on non-preferable host. About half (50\%) of the mosquitoes fed on non-preferable host in trial 1 . On the other hand, less than $30 \%$ fed on non-preferred host when the preferred one was present in trials 2 and 3 (Fig. 2).

\section{Discussion}

The findings of this study clearly indicate that Abate formulation is able to attract female An. gambiae s.s., and successfully emulated the chemical odour profile of a human host. Topical application of Abate on the furs of treated goat induced Anopheles mosquitoes to feed on the treated goat to a nearly equivalent degree

Table 1 Number and percentage and confidence intervals $(\mathrm{CI})$ of captured mosquitoes from untreated goats

\begin{tabular}{|c|c|c|c|c|c|c|c|c|}
\hline \multirow[t]{2}{*}{ Day } & \multicolumn{4}{|c|}{ Goat 1} & \multicolumn{4}{|l|}{ Goat 2} \\
\hline & No. & $\%^{a}$ & Lower Cl & Upper Cl & No. & $\%^{a}$ & Lower Cl & Upper Cl \\
\hline 1 & 123 & 28.15 & 20.20 & 36.09 & 108.00 & 24.71 & 16.58 & 32.85 \\
\hline 2 & 104 & 23.80 & 15.61 & 31.98 & 83.00 & 18.99 & 10.55 & 27.43 \\
\hline 3 & 8 & 1.83 & -7.46 & 11.12 & 10.00 & 2.29 & -6.98 & 11.56 \\
\hline 4 & 1 & 0.23 & -9.14 & 9.59 & 0.00 & 0.00 & 0.00 & 0.00 \\
\hline Total & 236 & 54.00 & 47.65 & 60.36 & 201.00 & 46.00 & 39.11 & 52.89 \\
\hline
\end{tabular}

a Percent captured is calculated from total captured i.e. captured in goat $1+$ goat 2

Table 2 Number, percentage and confidence intervals $(\mathrm{Cl})$ of captured mosquitoes on treated goats versus untreated goat

\begin{tabular}{|c|c|c|c|c|c|c|c|c|}
\hline \multirow[t]{2}{*}{ Day } & \multicolumn{4}{|c|}{ Treated goat } & \multicolumn{4}{|c|}{ Untreated goat } \\
\hline & No. & $\%^{a}$ & Lower Cl & $\overline{\text { Upper Cl }}$ & No. & $\%^{a}$ & Lower Cl & Upper Cl \\
\hline 1 & 91 & 6.06 & 1.16 & 10.96 & 31 & 2.06 & -2.94 & 7.07 \\
\hline 2 & 126 & 8.39 & 3.55 & 13.23 & 44 & 2.93 & -2.05 & 7.91 \\
\hline 3 & 267 & 17.78 & 13.19 & 22.36 & 126 & 8.39 & 3.55 & 13.23 \\
\hline 4 & 326 & 21.70 & 17.23 & 26.18 & 112 & 7.46 & 0.00 & 0.00 \\
\hline 5 & 245 & 16.31 & 11.69 & 20.94 & 134 & 8.92 & 4.09 & 13.75 \\
\hline Total & 1055 & 70.24 & 67.48 & 73.00 & 447 & 29.76 & 25.52 & 34.00 \\
\hline
\end{tabular}

a Percent captured is calculated from total captured i.e. captured in goat $1+$ goat 2

Table 3 Number, percentage and confidence intervals $(\mathrm{CI})$ of captured mosquitoes on untreated goat versus human host

\begin{tabular}{|c|c|c|c|c|c|c|c|c|}
\hline \multirow[t]{2}{*}{ Day } & \multicolumn{4}{|c|}{ Untreated goat } & \multicolumn{4}{|c|}{ Human } \\
\hline & No. & $\%$ & Lower Cl & Upper Cl & No. & $\%$ & Lower Cl & Upper CI \\
\hline 1 & 121 & 8.73 & 3.70 & 13.76 & 202 & 14.57 & 9.71 & 19.44 \\
\hline 2 & 45 & 3.25 & -1.93 & 8.43 & 184 & 13.28 & 8.37 & 18.18 \\
\hline 3 & 27 & 1.95 & -3.27 & 7.16 & 201 & 14.50 & 9.63 & 19.37 \\
\hline 4 & 73 & 5.27 & 0.14 & 10.39 & 241 & 17.39 & 0.00 & 0.00 \\
\hline 5 & 58 & 4.18 & -0.97 & 9.34 & 234 & 16.88 & 12.08 & 21.68 \\
\hline Total & 324 & 23.38 & 18.77 & 27.99 & 1062 & 76.62 & 74.08 & 79.19 \\
\hline
\end{tabular}




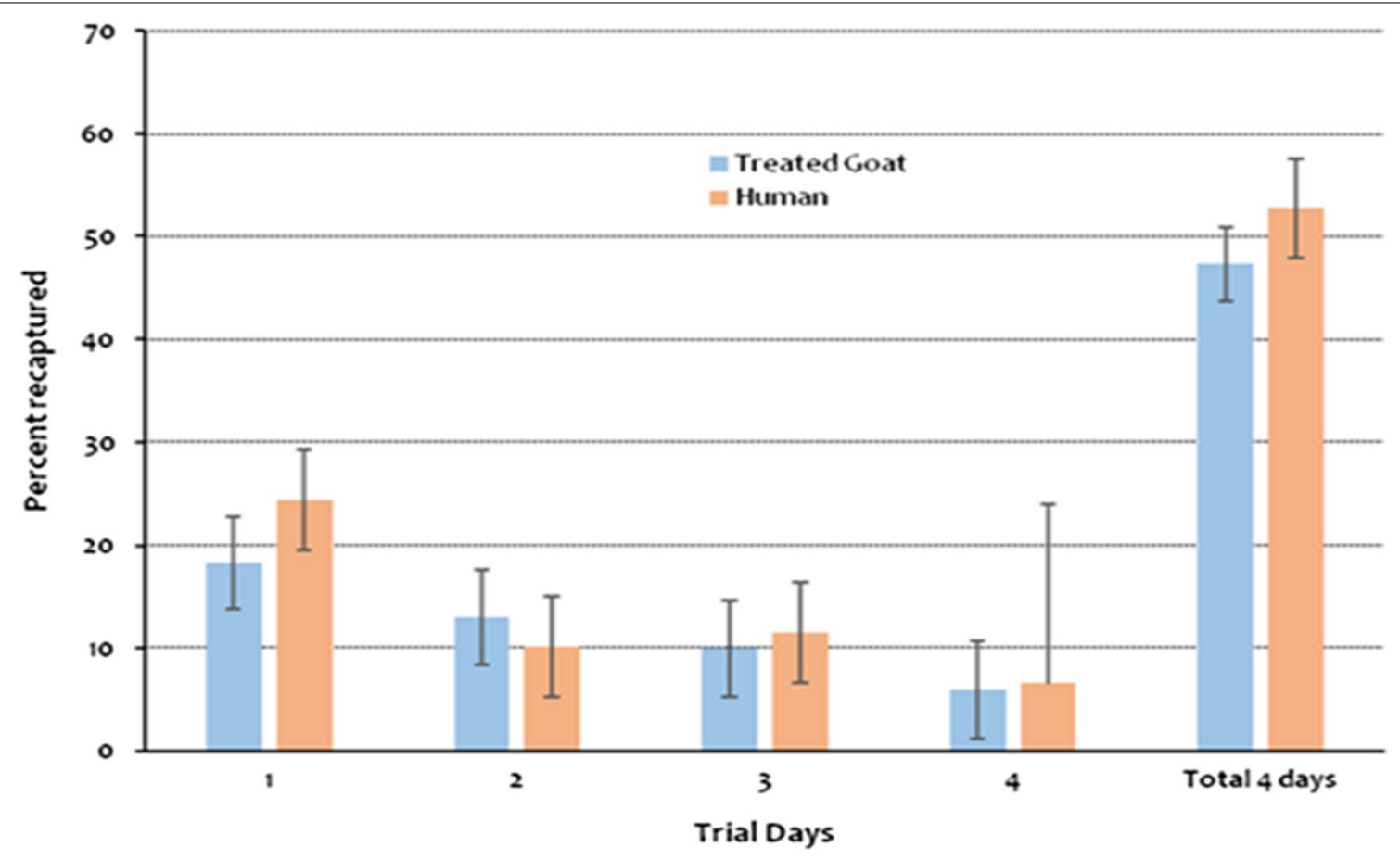

Fig. 1 Percentage of collected mosquitoes on Abate-treated goat versus human host

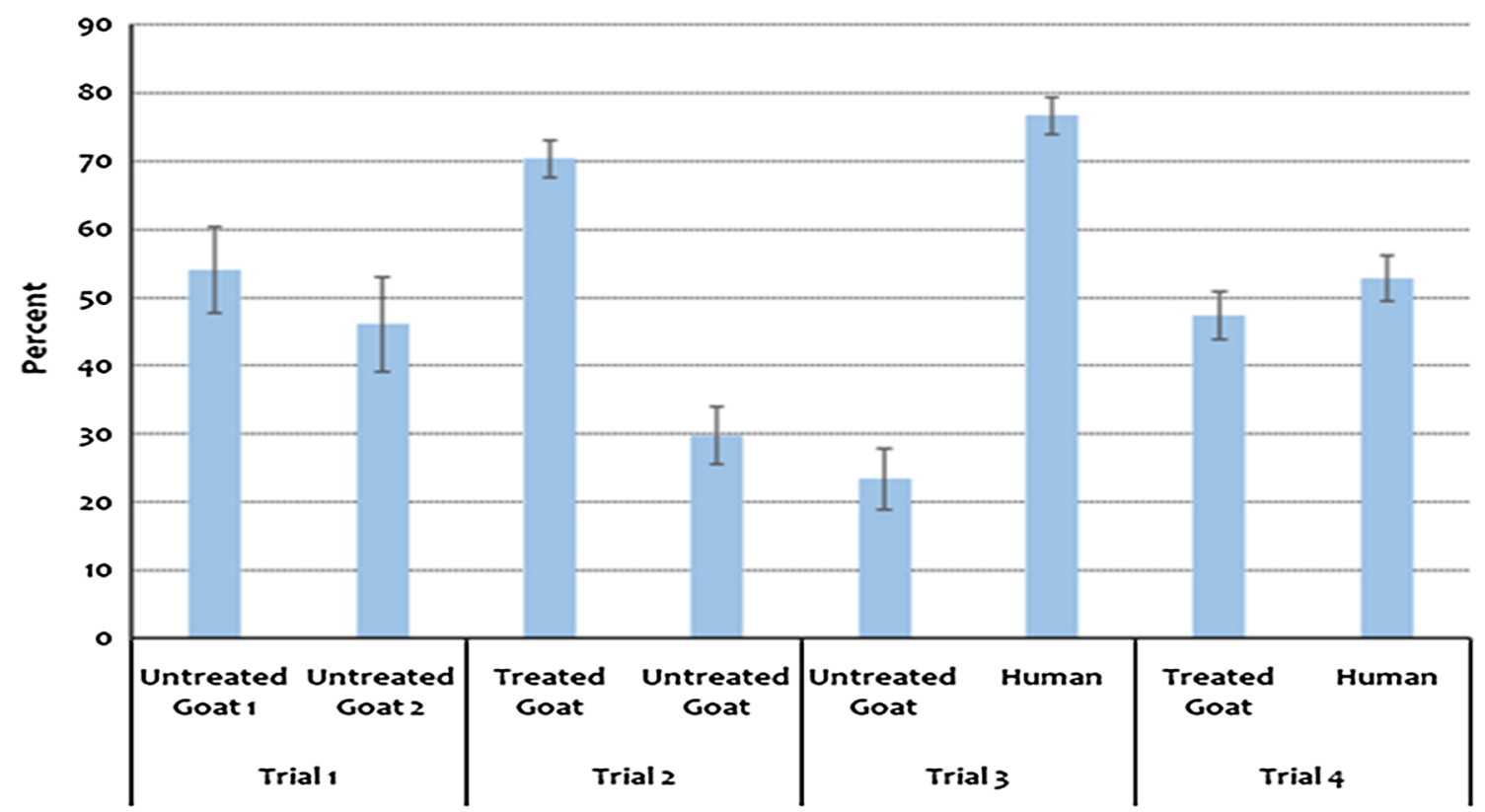

Fig. 2 Percentage of mosquitoes collected in the four trials

of the human host. Generally, the high rate of recapture of released mosquitoes suggest that majority of mosquitoes released into mosquito-sphere were hostseeking and chose one host or the other. The number of captured mosquitoes was much larger in trials involving Abate treatments and humans. Anopheles gambiae s.s. mosquitoes are known for their highly anthropophilic tendency in their feeding behaviour [30]. 
The findings that the number of collected mosquitoes declined from day 1 to 4 indicated that the mosquitoes are likely to have abilities to memorize the previous experience that the real host were not available in their vicinity, and hence reduced their searching activities.

Despite the presence of a human host in the same area, treatment with Abate diverted almost half of the captured mosquitoes into feeding on a non-preferred host. This shows that the use of zooprophylactic strategy in field settings could reduce inoculation rate and chances of malaria transmission to humans. The observed results elucidate that there is a potential in incorporating Abate with a killing agent (such as insecticide) to suppress a large number of mosquitoes in a single setting within a short time. The deployment of such a technique is likely to complement the current malaria mosquito control methods. This attract and kill technique relies not on conventional insecticides but on the synergy of two benign or beneficial components i.e. lactic acid as attractant already produced naturally by the animals themselves (hence, not introducing new component in the environments); and by administering orally based insecticides known to have low toxicity and requiring ingestion of the mosquito in order to work. The latter component provides an opportunity to counteract the challenges associated with contact insecticides. Furthermore, the unusually high levels of lactic acid emanating from Abate-treated animals may dissuade feeding by zoophilic mosquitoes that would otherwise select them as hosts. A previous study found that an artificial addition of non-host cues (lactic acid) to an otherwise suitable animal host often exerts a repellent effect on zoophilic host-seeking insects [17].

Despite the promising results observed in this study, further work is required to optimize the application of Abate formulation in real field settings. One possible potential shortcoming of the current Abate formulation could be the poor persistence of the material on the animal fur when exposed to normal weather during grazing or browsing. Weather conditions like rainfall and sunlight are likely to impact the persistence and effectiveness of Abate application over time [31]. It is equally important to be taken into consideration is how the distance between Abate-treated animals and human hosts to be protected will affect the formulation's performance. Therefore, further studies focusing on identifying the appropriate killing agent and the characterization of impacts of proximity of human host on the performance of the attractant are required.

\section{Conclusions}

Abate-treated goats were equally attractive to malaria mosquitoes as human hosts. Application of zooprophylactic strategy at the community level will likely reduce the number of mosquitoes encountering and feeding on humans, hence reducing malaria parasite transmission. Future studies should optimize the rate of Abate release and its persistence in different environmental conditions.

\section{Acknowledgements}

We are grateful to Amani Research Centre Management for their permission to utilize the mosquito spheres and supply of laboratory-reared mosquitoes. We would also like to thank Rukia Ahmed, Mathew Barabara and Kisesa Kasimu for their field assistance and rearing of mosquitoes. This study received financial assistance from Bill and Melinda Gates Foundation through ISCA Technologies.

\section{Authors' contributions}

LEGM, TD, AM, EEK conceived the idea and designed the study. TD, AP, EEK carried the statistical analysis. LEGM, TD, AM, JS, RS carried out and supervised the experiments. EEK, KJ, LEGM wrote the first draft of the manuscript. All authors read and approved the final manuscript.

\section{Funding}

This study received financial assistance from Bill and Melinda Gates Foundation through ISCA Technologies, Inc.

\section{Availability of data and materials}

All available data are included in this article.

\section{Ethics approval and consent to participate}

The study was approved by the Medical Research Coordinating Committee of the National Institute for Medical Research (Ref. No. NIMR/HQ/R.8a/Nol. $I X / 1584)$. Mosquitoes used in the experiments were raised in an insectary and free from infections. Human volunteers provided an informed consent before participating in the experiments.

\section{Consent for publication}

Not applicable.

\section{Competing interests}

The authors declare that they have no competing interests.

\section{Author details}

${ }^{1}$ Ministry of Health, Community Development, Gender, Elderly and Children, Vector Control Training Centre, Muheza, Tanzania. ${ }^{2}$ ISCA Technologies, Riverside, USA. ${ }^{3}$ University of Dar es Salaam, Dar es Salaam, Tanzania. ${ }^{4}$ Swedish University of Agricultural Sciences, Alnarp, Sweden. ${ }^{5}$ SACIDS Foundation for One Health, Sokoine University of Agriculture, Morogoro, Tanzania.

Received: 11 November 2019 Accepted: 22 January 2020

Published online: 30 January 2020

\section{References}

1. WHO. World malaria report 2018. Geneva: World Health Organization; 2018.

2. Paaijmans KP. Weather, water \& malaria - the impact of meteorological factors on water temperature and larvae of the Afro-tropical malaria vector Anopheles gambiae giles. PhD. Thesis-Wageningen University, The Netherlands. 2008. ISBN 978-90-8504-750-6.

3. WHO. World malaria report 2012. Geneva: World Health Organization; 2019.

4. WHO. World malaria report 2015. Geneva: World Health Organization; 2019.

5. Mboera LEG, Mazigo HD, Rumisha SF, Randall K. Towards malaria elimination and its implication for vector control, disease management and livelihoods in Tanzania. Malar World J. 2013:4:19.

6. Asidi A, N'Guessan R, Akogbeto M, Curtis C, Rowland M. Loss of household protection from use of insecticide-treated nets against pyrethroidresistant mosquitoes, Benin. Emerg Infect Dis. 2012;18:1101-6.

7. Koenker HM, Yukich JO, Mkindi A, Mandike R, Brown N, Kilian A, et al. Analysing and recommending options for maintaining universal coverage 
with long-lasting insecticidal nets: the case of Tanzania in 2011. Malar J. 2013;12:150.

8. White MT, Conteh L, Cibulskis R, Ghani AC. Costs and cost-effectiveness of malaria control interventions_-a systematic review. Malar J. 2011;10:337.

9. Ranson H, N'Guessan R, Lines J, Moiroux N, Nkuni Z, Corbel V. Pyrethroid resistance in African anopheline mosquitoes: what are the implications for malaria control? Trends Parasitol. 2011;27:91-8.

10. Cohen JM, Smith DL, Cotter C, Ward A, Yamey G, Sabot OJ, et al. Malaria resurgence: a systematic review and assessment of its causes. Malar J. 2012;11:122.

11. Protopopoff N, Matowo J, Malima R, Kavishe R, Kaaya R, Wright A, et al. High level of resistance in the mosquito Anopheles gambiae to pyrethroid insecticides and reduced susceptibility to bendiocarb in north-western Tanzania. Malar J. 2013;12:149.

12. Strode C, Donegan S, Garner P, Enayati AA, Hemingway J. The impact of pyrethroid resistance on the efficacy of insecticide-treated bed nets against African Anopheline mosquitoes: systematic review and metaanalysis. PLoS Med. 2014;11:e1001619.

13. Alonso PL, Brown G, Arevalo-Herrera M, Binka F, Chitnis C, Collins F, et al. A research agenda to underpin malaria eradication. PLoS Med. 2011;8:e1000406.

14. Mafra-Neto A, Saroli J, Oliveira da Silva R, Mboera LE, White GB, Foster W, et al. Getting them where they live-semiochemical-based strategies to address major gaps in vector control programs: Vectrax, SPLAT BAC, Trojan Cow, and SPLAT TK. In: Advances in the biorational control of medical and veterinary pests. SCS symposium series, 2018; p. 101-52.

15. Chaccour CJ, Kobylinski KC, Quique BQ, Bousema T, Drakeley C, Alonso P, et al. Ivermectin to reduce malaria transmission: a research agenda for a promising new tool for elimination. Malar J. 2013;12:153.

16. Mboera LEG, Knols BGJ, Takken W, Della Torre A. The response of Anopheles gambiae s.l. and A. funestus (Diptera: Culicidae) to tents baited with human odour or carbon dioxide in Tanzania. Bull Entomol Res. 1997:87:173-8.

17. Dekker T, Steib B, Cardé RT, Geier M. L-lactic acid: A human-signifying host cue for the anthropophilic mosquito Anopheles gambiae. Med Vet Entomol. 2002;16:91-8.

18. Zwiebel LJ, Takken W. Olfactory regulation of mosquito-host interactions. Insect Biochem Mol. 2004;34:645-52.

19. Mboera LEG, Takken W. Carbon dioxide chemotropism in mosquitoes (Diptera: (ulicidae) and its potential in vector surveillance and management programmes. Med Vet Entomol. 1997;85:355-68.
20. Acree F Jr, Turner RB, Gouck HK, Beroza M, Smith N. L-Lactic acid: a mosquito attractant isolated from humans. Science. 1968;161:1346-7.

21. Braks MAH, Meijerink J, Takken W. The response of the malaria mosquito, Anopheles gambiae, to two components of human sweat, ammonia and L-lactic acid, in an olfactometer. Physiol Entomol. 2001;26:142-8.

22. Knols BGJ, Njiru BN, Mathenge EM, Mukabana WR, Beier JC, Killeen GF. Malaria sphere: a greenhouse-enclosed simulation of a natural Anopheles gambiae (Diptera: Culicidae) ecosystem in western Kenya. Malar J. 2002:1:19.

23. Kline DL. Semiochemicals, traps/targets and mass trapping technology for mosquito management. J Am Mosq ContrAssoc. 2007;23:241-51.

24. Okumu FO, Killeen GF, Ogoma S, Biswaro L, Smallegange RC, Mbeyela E, et al. Development and field evaluation of a synthetic mosquito lure that is more attractive than humans. PLoS ONE. 2010;5:e895.

25. Ault SK. Environmental management: a re-emerging vector control strategy. Am J Trop Med Hyg. 1994;50(6 Suppl):35-49.

26. Saul A. Zooprophylaxis or zoopotentiation: the outcome of introducing animals on vector transmission is highly dependent on the mosquito mortality while searching. Malar J. 2003;2:32.

27. Sota T, Mogi M. Effectiveness of zooprophylaxis in malaria control: a theoretical inquiry, with a model for mosquito populations with two blood meal hosts. Med Vet Entomol. 1989:3:337-45.

28. Hewitt S, Kamal M, Muhammad N, Rowland M. An entomological investigation of the likely impact of cattle ownership on malaria in Afghan refugee camp in the North West Frontier Province of Pakistan. Med Vet Entomol. 1994;8:160-1.

29. Schorkopf DLP, Spanoudis CG, Mboera LEG, Mafra-Neto A, Ignell R, Dekker T. Combining attractants and larvicides in biodegradable matrices for sustainable mosquito vector control. PLoS Negl Trop Dis. 2016;10:e0005043.

30. Qiu YT, Smallegange RC, Hoppe S, van Loon JJ, Bakker EJ, Takken W. Behavioural and electrophysiological responses of the malaria mosquito Anopheles gambiae Giles sensu stricto (Diptera: Culicidae) to human skin emanations. Med Vet Entomol. 2004;18:429-38.

31. Aneth MM, Franklin WM, Johnson MM, Eliningaya JK. Role of cattle treated with deltamethrine in areas with a high population of Anopheles arabiensis in Moshi, Northern Tanzania. Malar J. 2007:6:109.

\section{Publisher's Note}

Springer Nature remains neutral with regard to jurisdictional claims in published maps and institutional affiliations.
Ready to submit your research? Choose BMC and benefit from:

- fast, convenient online submission

- thorough peer review by experienced researchers in your field

- rapid publication on acceptance

- support for research data, including large and complex data types

- gold Open Access which fosters wider collaboration and increased citations

- maximum visibility for your research: over $100 \mathrm{M}$ website views per year

At BMC, research is always in progress.

Learn more biomedcentral.com/submissions 